\title{
A Paixão de Jesus segundo
} François Cavanna

\author{
The Passion of Jesus according \\ to François Cavanna
}

Texto enviado em

29.02.2020

e aprovado em

27.04.2020

V. 10 - N. $20-2020$

*Doutor em Ciências da Religião, UMESP.

Realizou Pós-doutorado

pela Université Paris

Nanterre. É professor da

Universidade do Estado do

Pará e docente permanente do Programa de Pós-

Graduação em Ciências

da Religião. E-mail :

abismos@gmail.com

\section{Douglas Rodrigues da Conceição*}

\section{Resumo}

Partindo de uma perspectiva transtextual, o presente artigo propõe uma abordagem de Les aventures du petit Jésus, obra que foi escrita pelo jornalista e desenhista humorístico François Cavanna, um dos fundadores do jornal francês Charlie Hebdo. Junto com Les aventures de Dieu, Les aventures du petit Jésus formam uma única obra, que foi intitulada Les Écritures e publicada em 1982. Apoiando-se teoricamente em Gérard Genette - o que será feito a partir dos conceitos de paratextualidade e hipertextualidade tal como aparecem na obra Palimpsestes (1982) - toma-se como horizonte de análise as evidentes interconexões que Les aventures $d u$ petit Jésus estabelecem com Evangelhos canônicos da Bíblia. No presente estudo, Les aventures du petit Jésus são consideradas como reescrituras artísticas de narrativas que hipotextualmente pertencem aos Evangelhos bíblicos. O foco das análises recairá sobre a personagem central tanto dos Evangelhos quanto da obra de François Cavanna, a saber, Jesus. A Paixão de Jesus segundo Cavanna será o ponto de chegada do presente texto.

Palavras-chave: Bíblia, Jesus, H i pertextualidade, Paratextualidade, François Cavanna. 


\section{Abstract}

Starting from a transtextual perspective, this article proposes an approach of the work Les Aventures du Petit Jésus, written by the journalist and humourous cartoonist François Cavanna, one of the French journal Charlie Hebdo's founders. Along with Les Aventures de Dieu, Les Aventures du Petit Jésus forms a single work named Les Écritures published in 1982. Theoretically supported by Gérard Genette, what is going to be done from the paratextuality and hypertextuality concepts as they appear in Palimpsestes (1982), the interconnections which Les Aventures du Petit Jésus establishes with the Bible canonical gospels are taken as an analytical focus. In this study, Les Aventures du Petit Jésus are regarded artistic rewriting narratives that, hipotextually, belong to the biblical gospels. The analysis emphasis will traverse the main character of both the gospels and François Cavanna's work, Jesus. The Passion of Jesus according to Cavanna will be the final point of this article.

Keywords: Bible, Jesus, Hypertextuality, Paratextuality, François Cavanna.

\section{Introdução}

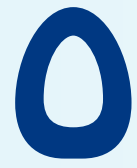

ano de 1982 foi marcado pela aparição de duas importantes obras claramente preocupadas em por evidência ao que provisoriamente chamaríamos de interconexão entre textos literários. Uma de dicção teórica, Palimpsestes, de Gérard Genette, e a outra de dicção artística, Les Écritures1, de François Cavanna, iluminaram, cada uma em seu próprio modo, o fenômeno das práticas transtextuais nos textos literários. 2

Gerárd Genette retomara em Palimpsestes (1982) problemas teóricos postos sob questão anos antes com a publicação da obra Introduction à l'architexte (1979) e que mais tarde retornariam à cena com a aparição de Seuils (1987). Preocupado com as múltiplas formas de interconexão estabelecidas entre textos, sobretudo os literários, Gérard Genette trouxe à lume, na obra de 1982, o conceito de transtextualida-

1. Doravante, para designar esta obra, utilizaremos a sigla $L E$.

2. A ausência de Cavanna nas reflexões empreendidas por Gérard Genette talvez seja explicada justamente em razão desta coincidência cronológica. 
de, que foi concebido para dar concretude a pelo menos cinco formas, manifestas ou mais secretas, de relações transtextuais. Para Genette, o conceito de transtextualidade superaria e absorveria a chamada de arquitextualidade, além de abrigar outras quatro modalidades: a saber: i) a intertextualidade, ii) a paratextualidade, iii) a metatextualidade e iv) a hipertextualidade.

A chamada intertextualidade é compreendida por Genette (1982, p. 8) como a modalidade que estabelece uma relação de co-presença entre dois ou vários textos, isto é, "[...] a presença efetiva de um texto num outro texto". Pela paratextualidade (1982, p. 9) e pela metatextualidade (1982, p. 11) os textos põe em evidência suas funções metalinguísticas. Um título, um subtítulo ou outros elementos que não estejam "diretamente" consignados em uma narrativa, poema ou texto dramático, por exemplo, podem fazer remissão direta ao conteúdo do próprio texto e isso caracteriza o fenômeno paratexto. A metatextualidade se caracteriza frequentemente pelo comentário que une um texto a um outro texto. A hipertextualidade (1982, pp. 11-16) descreve toda relação que une um texto $B$, chamado de hipertexto, a um texto $A$, chamado de hipotexto, de forma que exista a evidência de que $B$ seja derivado de $A .{ }^{3} E$, por fim, a chamada arquitextualidade se realiza, em expressão própria de Genette (1982, p. 12), por meio de uma relação muda e basicamente determinada por propriedades genéricas das obras, em termos de pertença a um determinado gênero literário.

Diante de um puro exercício artístico, François Cavanna, que foi fundador do jornal humorístico Charlie Hebdo, publicou LE em 1982, cujo projeto literário seria o de reescreever a Bíblia. Essa interessante

3. Um recente estudo de autoria de Eli Brandão da Silva e Huerto Eleutério Pereira de Luna nos oferece um excelente horizonte acerca da modalidade hipertextualidade sob a ótica de Gérard Genette, em Palimpsestes. Cf. SILVA, Eli Brandão da; LUNA, Huerto Eleutério Pereira de. Salmos e Evangelhos por paródias, em poéticas de Luis Augusto Cassas e Murilo Mendes. Estudos de Religião, São Bernardo do Campo, v. 33, n. 3, 2019: 15-35. 
obra está dividida em duas grandes partes: Les aventures de Dieu ${ }^{4}$ e Les aventures du petit Jesus ${ }^{5}$. Sob um ângulo propriamente hipotextual - para adotar de início uma linguagem genetteana - o primeiro conjunto de histórias estaria vinculado ao AT e o segundo ao NT. Assim, o projeto artístico de Cavanna ancorou-se fundamentalmente num tipo de deslizamento de personagens e de narrativas da Bíblia para $L E$.

Pertencente à linhagem de Alfred Jarry, artista que ao menos para o século XX poderia ser considerado uma espécie de precursor do uso dos textos da Bíblia como matéria prima artística para a literatura pensamos aqui mais propriamente em La passion considérée comme course de côte, de 1903, François Cavanna, dotando LAPJ de traços criativos peculiares e modulações narrativas, reescreve várias histórias e personagens dos Evangelhos bíblicos. Em razão da impossibilidade de abarcar todas as unidades narrativas pertencentes ao que por nossa conta e risco chamaríamos de os Evangelhos segundo Cavanna - muito embora sobrevoaremos algumas delas - o presente artigo configurar-se, portanto, como uma tentativa de apresentação de nuances do processo reescriturístico do humorista francês, a partir do núcleo narrativo da Paixão de Jesus.

\section{O paratexto e a obra}

Mesmo que dentro do século XX o uso estético da Bíblia pelas várias expressões artísticas estivesse sob críticas e ensejasse desconfianças no que tange ao valor artístico dos objetos artísticos derivados das artes que utilizaram as Santas Escrituras como matéria prima, seria importante pensar, por outro lado, é e por este ângulo que procuramos compreender a questão das reescrituras bíblicas, tal como muito bem sublinhou Catherine Grenier (2003, p. 5), que o que deve ser posto em questão, em última análise, seria antes a riqueza das referências religio-

4. Doravante, para designar esta parte de Les Écritures ( $L E)$, utilizaremos a sigla $L A D$.

5. Doravante, para designar esta parte de Les Écritures ( $L E)$, utilizaremos a sigla LAPJ. 
sas para a criação artística. Vejamos o que diz Grenier a esse respeito:

Alors que les Christs, les Vierges, les Enfers et les Paradis se font légion dans l'art contemporain, on est amené à se demander si cette résurgence iconographique n'a pour unique raison d'être que la réhabilitation et la manipulation subversive d'une iconographie traditionnelle, ou si elle forme le symptôme d'une véritable réinvention de la référence religieuse menée par les nouvelles générations d'artistes ${ }^{6}$ (GRENIER, 2003, p. 6).

Pensando no projeto estético de Cavanna, diríamos, pois, que o audacioso propósito de reescrever as narrativas de Deus e de Jesus deve ser compreendido dentro de um quadro de criação artística. Nisto insistiremos. A presença transparente ou mesmo implícita dos textos das santas Escrituras num poema, num romance ou num texto dramatúrgico, por exemplo, nos permitiria admitir que tal ocorrência deriva antes de uma intencionalidade estética do poeta, do romancista ou do dramaturgo. Não por acaso, um dos interesses de Catherine Grenier em L'art contemporain est-il Chrétien ? (2003), entre outros, seria o de demonstrar, por exemplo, que a figura do Cristo ainda inspira esteticamente muitos artistas contemporâneos. Em nosso caso, o uso artístico da Bíblia poderia ser pensado como um tipo de matéria prima intencionalmente implicada ao processo criativo do texto literário. $\mathrm{Ou}$ seja: a ocorrência da Bíblia nos textos literários, seja qual for o gênero, seria uma evidência de que ela participa, em algum nível, do respectivo modo de existência de tais expressões literárias.

A transparência da Bíblia em $L E$ de Cavanna se dá de modo manifesto e ostensivo desde o uso do paratexto que nomeia a obra. Laurent Gervereau (1997, p. 50) lembra-nos muito bem que o título de uma obra, concebido ou não pelo autor, se constitui, frequentemente,

6. "Enquanto Cristos, virgens, infernos e paraísos se fazem numerosamente presentes na arte contemporânea, somos induzidos a questionar se este reaparecimento iconográfico não teria como única razão a reabilitação e a manipulação subversiva de uma iconografia tradicional ou se ele revela o sintoma de uma verdadeira reinvenção da referência religiosa apresentada pelas novas gerações de artistas". GRENIER, Catherine. L'art contemporain est-il chrétien? Nîmes: Jacqueline Chambon, 2003. 
como um pilar central de sentido. Para Genette, em Seuils (1987), obra consagrada especificamente ao estudo dos paratextos, seria quase impossível pensar a existência de uma obra literária sem o reforço de um certo número de produções verbais como um nome de autor, um título, um prefácio, ilustrações [...] (GENETTE, 1987, p. 7)". "Mais do que um limite ou uma fronteira estanque”, afirma Genette (1987, p. 7), "trata-se de um limiar [...], que oferece a cada um a possibilidade de entrar, ou retroceder" (1987, p. 8). Em associação ao que já foi dito acima, os paratextos seriam, portanto, o que faz um texto se tornar um livro e assim sendo se propõe como tal aos leitores. Enfatizando a importância dos paratextos, Genette nos oferece um exemplo bastante esclarecedor: "reduzidos apenas ao texto e sem o auxílio de nenhum modo de usar, como leríamos o Ulysses de Joyce se não se intitulasse Ulysses? (GENETTE, 1987, p. 7)".

A primeira edição de $L E$ (1982), do ponto de vista do projeto visual da capa, talvez não diga muito acerca do conteúdo da obra e do seu elo como a Bíblia. A editora Albin Michel, no entanto, na edição de 2002, procurou estabelecer uma conexão entre o paratexto verbal utilizado no título obra, o conteúdo da obra e o novo projeto gráfico para o livro. Vejamos abaixo:

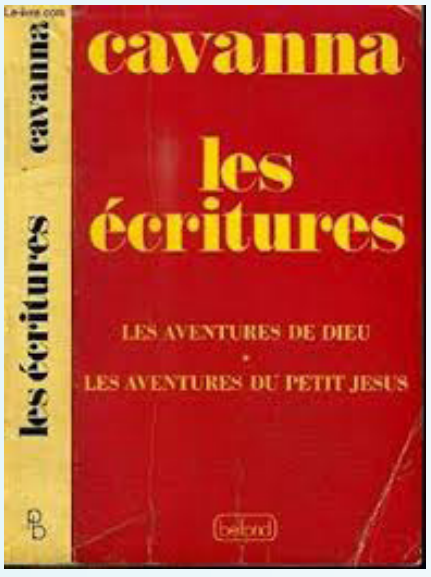

Belfond: 1982

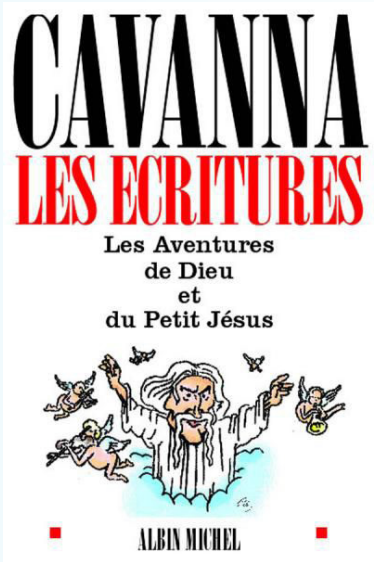

Albin Michel: 2002 
É evidente que a escolha de um ou mais paratextos - o paratexto enquanto elemento indispensável ao acesso à obra e como caminho para a constituição de sentido - considera sobremaneira o universo dos leitores. Podemos assim dizer que, enquanto estratégia de criação literária, as infiltrações bíblicas que Cavanna deixa a céu aberto em $L E$ pressupõem que as modulações narrativas criativamente concebidas por ele, e que estão presentes na sua obra, serão facilmente correlacionáveis com as respectivas narrativas da santas Escrituras pelos leitores e que por isso mesmo a instauração da novidade artística não visa ao obscurecimento do texto fonte (os hipotextos); ao contrário, diríamos: é importante que os leitores reconheçam a Bíblia em $L E$, de modo que o novo texto, o palimpsesto, numa percepção genetteana, a faça o mais perceptível possível na superfície mesma da obra recriada, isto é, reescrita. A título de ilustração, poderíamos evocar os primeiros "versículos" de $L A D$ :
1. Au commencement, Dieu créa le ciel et la terre.
2. Non.
3. Ce n'est pas comme ça.
4. Reprenons depuis le début.
1. Au commencement, il y avait Dieu.
2. Et rien d'outre.
3. II ne pouvait y avoir rien d'autre car, pour qu'il y eût quelque chose, il eût fallu que Dieu l'eût créé,
4. Or Dieu n'avait encore rien créé ${ }^{7}$ (CAVANNA, 2002, p. 11)

7. Citaremos no corpo do texto a edição de LE, de Albin Michel (2002). CAVANNA, François. Les Écritures: les aventures de Dieu et du petit Jésus. Paris: Albin Michel, 2002. Utilizaremos a edição portuguesa, cuja tradução foi realizada por Luis Pignatelli. CAVANNA, François. As Sagradas Escrituras. Tradução de Luis Pignatelli. Lisboa: Publicações Dom Quixote, 1986. A manutenção do texto original no corpo do artigo procura oferecer uma forma de acesso ao leitor às entonações artísticas e humorísticas de Cavanna, que eventualmente não foram capturadas pela belíssima tradução de Luis Pignatelli.

"1. No princípio. Deus criou o céu e a terra.

2. Não.

3. Não foi assim.

4. Retomemos o discurso desde o princípio.

1. No princípio, havia Deus.

2. E mais nada.

3. Não podia haver mais nada porque, para haver qualquer coisa, era preciso que Deus a criasse.

4. Ora, Deus ainda não tinha criado nada”. CAVANNA,1986, p. 13. 
Mesmo ao leitor pouco familiarizado com o livro de Gênesis, seria possível estabelecer uma direta correlação com as narrativas das origens do mundo. Os paratextos de Albin Michel amplificam as possibilidades de entrada do leitor no universo escriturístico bíblico e por conseguinte com o universo reescriturístico de Cavanna. A capa concebida por Albin Michel põe em evidência não só uma das representações mais caricaturais de Deus, isto em razão da figuração desta personagem em cabelos brancos, mas também àquela de Jesus, comumente retratada com cabelos longos. A personagem na capa não seria, no entanto, uma dupla representação (Deus-Jesus) e sim tripla (DeusJesus-Cavanna). A personagem que aparece com longos bigodes é uma caricatura do próprio François Cavanna. Logo, tal personagem seria a um só tempo uma caricatura de Deus, de Jesus e do próprio autor das reescrituras. Outros elementos remetem o leitor ao universo religioso da Bíblia. A figuração das nuvens, de onde "brota" a personagem central, o longo vestido branco, figurino recorrente em múltiplas representações de Deus e também de Jesus, e os anjos, seres relacionados ao mundo celeste - sem precisar dizer da expressiva presença de anjos na Bíblia e em múltiplos imaginários religiosos - são importantes dimensões paratextuais da obra de Cavanna. Seria interessante sublinhar que os anjos da capa de Albin Michel aparecem tocando instrumentos musicais. Um dos anjos é representado portando uma trombeta. A vocação lúdico-humorística desta edição já se anuncia aí. Poderíamos falar de um tipo de potencialização semântico-paratextual. O sema trombeta é associado de modo icônico ao livro de Apocalipse do NT. Assim posto, podemos dizer que a dimensão plurissignificativa da obra é em parte condicionada pelas chaves de recepção (leitura) do leitor. A depender do leitor, diríamos que a capa da Albin Michel convoca para o universo de significação do humorista o Apocalipse do NT. É possível afirmar, portanto, que LE de Cavanna procuram movimentar a percepção estética do leitor por meio de sua capacidade de capturar, pela leitura, as referências bíblicas, explicitas e/ou implícitas, que estão presentes em sua obra. 


\section{A poética hipertextual de Cavanna}

Pensar os quatro Evangelhos mais conhecidos e suas respectivas unidades narrativas enquanto hipotextos de outros textos não é uma tarefa nova. Aliás, em se tratando de relações transtextuais entre textos verbais os próprios Evangelhos são um imenso e inabordável oceano. ${ }^{8}$ Mesmo tendo já evocado o importante escopo teórico construído por Genette, não vemos nenhum motivo para não reforçar o que já dissemos. Julia Kristeva (1974) chamava já à atenção - antes mesmo de Genette ao antever que nenhum texto pode ser redigido independentemente dos que já foram escritos. Os próprios textos dos Evangelhos não seriam, portanto, uma exceção. Quanto à perspectiva das relações transtextuais entre os Evangelhos e a literatura não-bíblica, no panorama brasileiro, o trabalho de Eli Brandão da Silva (2001) deve ser destacado como uma importantíssima referência. Em sua tese de doutorado - partindo do que chamou de "hermenêutica transtexto-discursiva" -, Silva demonstrou de modo lapidar as particulares relações transtextuais e interdiscursivas que o poema obra Morte e Vida Severina, de João Cabral de Melo Neto, estabelece com os Evangelhos de Mateus e Lucas.

LAPJ são compostas por 11 capítulos. A poética transtextual de Cavanna leva em consideração detalhes importantes. Numa perspectiva que poderíamos chamar de arquitextual, tanto $L A D$ quanto $L A P J$ obedecem à estrutura de capítulos e versículos tal como na Bíblia. É importante sublinhar este detalhe, pois nem todo projeto artístico que considera a Bíblia como matéria prima procura tal correspondência arquitetural. Cada capítulo da obra, de modo geral, comporta mais de um conjunto de narrativas compostos por versículos. O capítulo 11 - que aqui nos interessa em particular - contém três conjuntos, sendo o primeiro composto por 30 versículos e o segundo e o terceiro compostos por 29 versículos cada um. O que poderíamos afirmar de início é que de modo inconteste

8. ZUMSTEIN, Jean. Intratextualité et intertextualité dans la littérature johannique. In: CLIVAZ, Claire [et al.]. Écritures et réécritures: la reprise interprétative des traditions fondatrices par la littérature biblique et extra-biblique. Peeters: Leuven, 2012, p. 331. 
$\angle A P J$ retomam, em nível contratual, várias unidades narrativas acerca da personagem Jesus dos Evangelhos bíblicos. Poderíamos afirmar ainda que $L A P J$ de Cavanna, ao reescreverem as narrativas de Jesus e ao oferecerem uma outra codificação para esta personagem, ficaram longe dos riscos uma cacofonia literária. A obra de Cavanna nos permitiria a seguinte postulação: nenhum artista deseja criar o mesmo, o já criado. O artista mira sempre, e assim postulamos, o novo, o outro (não em termos éticos, mas em termos estéticos), em suma, a novidade artística. É neste sentido que reconhecemos $\angle A P J$ de Cavanna como um belo exemplo de hipertexto. ${ }^{9}$ No caso de $L A P J$ - como já nos entrega o próprio paratexto que nomeia o "segundo testamento" de Cavanna - temos a retomada explícita da personagem central dos Evangelhos canônicos, a saber, Jesus; temos ainda a convocação de diversas unidades narrativas (o nascimento de Jesus, a história dos três reis magos, a narrativa da genealogia de Jesus, o episódio do batismo de Jesus, a tentação de Jesus, as bodas de Canaã, o sermão da montanha, a cura do leproso, a cura do escravo do centurião, a parábola do semeador, o milagre da multiplicação dos pães e dos peixes, o episódio do gadareno possuído, a transfiguração de Jesus etc.) e, é claro, uma plêiade de personagens (José, Maria, Herodes, os apóstolos, Maria Madalena, Judas, Caifás, Pilatos, Simão de Cirene, etc.).

A demarcação dos hipotextos, aqui os textos dos Evangelhos mais conhecidos, e cujo caminho demarcatório poderíamos fazer desde as portas de entrada para o texto (o que acima chamamos de paratexto), se dá evidentemente no texto de segundo nível, ou seja, no hipertexto. Dito assim, LAPJ de Cavanna, em nossa ótica, estabelecem uma relação hipertextual por transformação, que oscila entre a "parodie" e o "travestissement", sendo tal relação presidida por um regime que pendula

9. Para Genette as operações hipertextuais podem se dar por imitação ou por transformação (pensamos ainda na possibilidade da simultaneidade de ambas). O fenômeno que se apresenta seria o de "dire la même chose autrement/dire autre chose semblablement”. GENETTE, Palimpsestes. Paris: Éditions du Seuil, 1982, p. 13. 
entre o lúdico e o satírico ${ }^{10}$. Considerando a diafania dos hipotextos, a operação transtextual chamada travestissement do tipo burlesco, o que nos parece ser o caso das aventuras do menino Jesus, sob as lentes genetteanas, seria então caracterizada pela sua capacidade de reescrever o texto de partida (o hipotexto) conservando muitos aspectos de sua ação, mas impondo-lhe uma outra escritura, o que então pode ensejar a emergência de um novo terreno de significação para o texto reescrito. Para Genette (1982, p. 88) o travestissement seria, portanto, "um exercício de versão".

$\mathrm{Na}$ Bíblia de Cavanna, as reescrituras das narrativas de Jesus ganham contornos ostensivamente humorísticos. O nascimento de Jesus acontece depois de um longo colóquio realizado entre o Deus, Jesus e o Espírito Santo. A verve humorística de Cavanna é perceptível em toda obra. Recuperando, por exemplo, Mt 3:11, o batismo de Jesus é decidido com João depois de uma aposta de cara ou coroa. A narrativa da tentação de Jesus pelo diabo recebe adições não menos satíricas. Estando então Jesus no deserto, a Bíblia de Cavanna nos conta que muitas pessoas vinham de longe para ver Jesus jejuar e que ao redor dele se sentavam. O elemento criativo, por exemplo, entre outros relacionados à narrativa, fica por conta da inclusão de vendedores de gaufre e de linguiça merguez entre a multidão. Em explícito movimento transtextual, na sequência da história, o Jesus de Cavanna recita quase que literalmente Mt 4:4 para o diabo.

O episódio da cura do leproso é um dos mais jocosos. O hipotexto usado por Cavanna para estruturar seu hipertexto é Mt 8:1. E como Jesus não havia compreendido bem o que o leproso tentava lhe dizer, isto em razão dos lábios inchados do doente, decidiu então que de qualquer forma algo deveria ser feito ao enfermo. O Jesus do humorista deu ao leproso o dom de mexer as orelhas. $E$ querendo o leproso dizer algo a Jesus, este dizia ao doente que não havia necessidade de agradecer,

10. GenetTE, Op. Cit. 
pois tudo fora feito com bom coração. Como uma espécie de prescrição médica disse ainda ao leproso de lábios inchados: "[...] Va et sois heureux. Et ne mange pas trop de fraises, elles donnent de l'urticaire"'11 (CAVANNA, 2002, p. 272).

Outro jocoso episódio de cura é o do escravo do centurião. Convocando Mt 8:5-6, neste episódio o Jesus de Cavanna diz ao centurião que sua agenda de consultas estava cheia e que logo que possível passaria pela sua casa para ver o enfermo. E a narrativa prossegue dando-nos conta de um Jesus que curava muitos doentes de maneira fantástica:

25. Aux boiteux il faisait pousser une troisième jambe, aux aveugles il faisait cadeau des hémorroïdes, aux poitrinaires il envoyait la dysenterie afin qu'ils n'osassent plus tousser, 26. Et aux culs-de-jatte il faisait croître une poignée sur la tête afin qu'ils pussent gagner leur vie en qualité de fers à repas$\operatorname{ser}^{12}$ (CAVANNA, 2002, p. 274)

O Evangelho de Cavanna narra também o que teria sido o primeiro encontro entre Jesus e Maria Madalena. A narrativa nos conta que uma mulher tinha ido ao encontro de Jesus. Ao ser perguntada qual seria a doença que a levara até ele, Maria Madelena teria respondido se tratar de ninfomania: "Je suis nymphomane" (CAVANNA, 2002, p. 288). Na sequência Jesus lhe diz que se caso tivesse fé estaria então curada. Maria Madalena responde não ter ido até ele para ser curada de sua ninfomania: “'Mais je ne suis pas venue pour ça ! Pas du tout!' Et ses yeux brillaient, et elle l'emmena chez elle, et ainsi commença l'amitié de Jésus

11. “'6. [...] Vai e sê feliz. E não comas muitos morangos, fazem urticária”'. CAVANNA, 1986, p. 222.

12. "25. Aos coxos fazia-lhes crescer uma terceira perna, aos cegos fazia-lhes hemorróidas de presente, aos fracos de peito dava-lhes disenteria para que não tivessem mais forças para tossir.

26. $E$ aos pernetas fazia-Ihes crescer uma pega na cabeça para poderem ganhar a vida como ferros de engomar". CAVANNA, 1986, p. 223. 
et de Marie-Madeleine"13. Os Evangelhos de Cavanna contam ainda que Jesus percorria toda Galileia dizendo parábolas e oferecendo todo tipo de serviço. As pessoas lhe faziam pedidos que iam desde a cura de paralíticos até o desentupimento de pias. ${ }^{14}$

A narrativa da cura da mulher que sofria por 12 anos com hemorragia e que está presente, por exemplo, em Mt 9:20 e Lc 8:43, torna-se em Cavanna a narrativa de uma mulher sofria de "d'hémorroïdes effroyables". Aliás, o uso do sema hemorroidas aparece em várias narrativas de $\angle A P J$. Cavanna tira proveito da homologia gráfica e fonética existente entre as palavras "hémorroïdes" e "hémorroisse", na língua francesa, para explorar a dimensão grafia-som-sentido.

O Jesus de Cavanna é uma personagem dotada de bom humor. Em clara relação transtextual com o que se passa em Mt 16:13-18, Jesus chama Pedro e lhe faz um trocadilho. Com o coração palpitante pela deferência do mestre - assim diz o Evangelho de Cavanna - Pedro ouve o seguinte de Jesus: "[...] Voici. C'est un très joli calembour. Je l'ai fait tout exprès pour toi. Écoute bien : Pierre, tu es pierre, et pierre qui roule n'amasse pas mousse. Elle est bonne, hein ?"15 (CAVANNA, 2002, p. 290). Em ostensiva

13. "5. '[...] Mas eu não vim para isso! Não!' E os seus olhos brilhavam, e ela levou-o para sua casa, e assim começou a amizade de Jesus e de Maria Madalena'". CAVANNA, 1986, p. 234.

Maria-Madalena aparece novamente nos Evangelhos de Cavanna de braços dados com Jesus em dois momentos. Em narrativas precedentes, Maria Madelena figura nas $\angle P A J$ aquela que cuidou dos pés de Jesus e que os massageava com os seus seios e como aquela que esquentava os pés do mestre pondo-os entre suas pernas.

14. 2. "Et l'un lui disait: 'Seigneur, mon fils est paralytique' ou : 'mon vieux père mange beaucoup pour son âge' ou : 'L'évier est bouché’”. CAVANNA, 2002, p. 285.

3. "Et Jésus faisait ce qu'il fallait, et ils étaient guéris, et l'évier était débouché, et ils s'écriaient: 'Tu es vraiment le fils de Dieu ! Serre-moi la main, mon pote. Allez, viens boire un pot avec moi. Refuse pas, tu me vexerais'”. CAVANNA, 2002, p. 285.

"2. E um dizia-Ihe: 'Senhor, o meu filho está paralítico' ou: 'O meu velho pai come muito para a sua idade' ou: 'A pia está entupida'”. CAVANNA, 1986, p. 232.

"3. E Jesus fazia o que era preciso, e eles ficavam curados, e a pia ficava desentupida, e gritavam: 'Tu és realmente o Filho de Deus! Aperta-me a mão, rapaz. Anda, vem beber um copo comigo. Não recuses, vexar-me-ias'”. CAVANNA, 1986, p. 232.

15. "6. E Jesus disse-lhe: 'Aqui está. É um trocadilho muito bonito. Fi-lo expressamente para ti. Escuta bem: Pedro, tu és pedra, e pedra que rola não amassa mousse. $E$ boa, hã?'” CAVANNA, 1986, p. 235. 
relação com Mt 16:15-16, o trocadilho feito pelo Jesus improvisador, e que foi dedicado a Pedro, teve motivação na resposta dada pelo apóstolo: "Seigneur, tu es le Messie, le Fils du Dieu vivant"16 (CAVANNA, 2002, p. 289). A sequência da narrativa nos conta que todos os demais discípulos riram e disseram o seguinte a Jesus: "Oh, qu'elle est bonne, Seigneur! Oh, vous, alors, vous êtes impayable, Seigneur! Oh, Seigneur, je fais pipi sous moi, Seigneur !" (CAVANNA, 2002, p. 290).

O risível se translucida, assim, como o efeito estético buscado pela poética hipertextual da obra de Cavanna. No caso da Paixão de Jesus, arriscaríamos dizer que não se trataria daquilo que comumente se chama de esvaziamento do sentido trágico da Paixão quando este sema dos Evangelhos é reescrito sob o signo do humorístico. Mireille Losco-Lena diria que em poéticas complexas, como LAPJ de Cavanna, é possível entrever a simultaneidade do trágico ("chant du bouc") e do cômico ("chant du cochon"). $L A P J$, em diversos momentos, ligam o "bouc" ao "cochon". Isto é: "la mise en scène de la mort et les émotions douloureuses qui lui sont liées sont traversées, voire travesties, par une étrange - voire terrible - drôlerie"17 (LOSCO-LENA, 2012, p. 5).

\section{A Paixão segundo Cavanna}

Chegando o momento de Jesus ir até Jerusalém, a fim de que as Escrituras fossem então cumpridas, o herói de Cavanna foi advertido pelo Eterno Deus a não se ladear com "femmes de mauvaise vie", mas antes se concentrar no trabalho para o qual fora encarnado. Os discípulos de Jesus, em Cavanna, ficaram radiantes com a notícia dada pelo mestre. "Chic ! Chic !, disseram!" (CAVANNA, 2002, p. 302). Neste relato, Jerusalém é figurada, por ser páscoa, uma época de festas, como

16. "2. 'Senhor, tu és o Messias, o Filho do Deus vivo!" CAVANNA,1986, p. 235.

17. "A encenação da morte e as penosas emoções atadas a ela são atravessadas, na verdade travestidas, por uma estranha - ou mesmo terrível - comicidade". LOSCOLENA, Mireille. Tragique et comique sur les scènes contemporaines: pour une "poétique complexe". Publications numériques du CÉRÉdl (Actes de colloques et journées d'étude. Rouen, n. 7, 2012: 1-11. 
uma cidade cheia de atrativos: '[...] II va y avoir des guirlandes, et des lampions, et des marchands de gaufres, et des montreurs d'ours, et des danses du ventre ! [...]"18 (CAVANNA, 2002, p. 302).

O herói de Cavanna pôs-se em rota acompanhado de uma multidão, assim diz o Evangelho do humorista. Além dos doze apóstolos, Jesus era seguido por Maria Madalena - "avec son nécessaire de pédicure" - e Martha sua irmã - "avec ses chaudrons et ses marmites". Mas não para por aí. O Jesus de Cavanna tinha ainda a companhia de: "Jeanne, femme de Chuzas, et Sussanne-la Grêlée, et Lulu-la-Péniche, et RaymondeFesses-de-Bronze, et encore beaucoup d'autres femmes,"19

E ainda:

14. [...] Et il y avait aussi Lazare, le frère de Marthe et MarieMadeleine, que Jésus avait ressuscite après qu'il eut été quatre jours mort parmi les morts, et qui avait gardé la joue un peu creuse, la mine un peu verte et la narine peu foisonnante d'asticots,

15. Et il y avait aussi des Samaritaines et des hémorroïsses, et des sourds-muets et des aveugles,

16. Et des boiteux, des goitreux, des lépreux, des pesteux, des galeux, des morveux, des pisseux, des croûteux, des gâteux, des chiasseux, des vaseux, des bigleux,

17. Et des possédés, des enragés, des siphonnés, des pommadés, des brûlés,

18. Et des fils prodigues, des pères indignes, des mères maquerelles, des filles publiques, des frères siamois, des bébés phoques, des démons repentis, des chameaux qui avaient essayé de passer par le trou d'une aiguille,

19. Et des pharisiens, des publicans, des radicaux-socialistes, des pédérastes, des rastaquouères, des officiers ministériels, des toréadors, des paltoquets, des tondeurs de chiens, des châtreux de chats, des circonciseurs-jurés, des antisémites, des mirliflores, des danseurs de claquettes, des fins gourmets, des messies qui avaient tenté le coup mais qui n'avaient pas eu de chance,

20. Et des paniers percés, des gobe-la-lune, des bas-du-cul, des pique-assiette, des guette-au-trou, des boit-sans-soif, des

18. "6. [...] Vai haver grinaldas, e lampiões, e mercadores de filhós, e amestradores de ursos, e danças do ventre! Que bom! Que bom!" CAVANNA, 1986, p. 246.

19. "8. E também Joana, mulher de Chuzas, e Susana-a-bexigosa, e Lulu-a-Chalupa, e Raimunda-Nádegas-de-Bronze, e ainda muitas outras santas mulheres, [...]" CAVANNA, 1986, pp. 246-247. 
dort-en-chiant, des peine-à-jouir, des compères-loriots, des têtes-à-gifles, des pisse-trois-gouttes, des maries-salopes, 21. Et des gens qui étaient sortis s'acheter des allumettes, et des gens qui étaient sortis pour aller se noyer ${ }^{20}$ (CAVANNA, 2002, pp. 303-304).

Jesus entra em Jerusalém montado num asno. Judas também aparece nas reescrituras de Cavanna como a personagem que trai o mestre. No capítulo 9, o discípulo traidor (“Judas, mon vieux cochon, c'est toi qui feras le traîter"21 (CAVANNA, 2002, p. 309), disse-lhe Jesus) vai até Caifás, cujo palácio havia inscrições esculpidas em mármore, tais como: 'Trahissez, nous ferons le reste'. ${ }^{22}$

A chamada "última ceia" também aparece no Evangelho de Cavanna. Tendo partido o pão e dado o alimento aos discípulos - que comeram e "estalaram a língua" -, Jesus serve-lhes vinho. Segundo os discípulos, o vinho, o sangue de Jesus, era um "bocado insípido" e então sugeriram ao mestre que o metesse "numa tripa, com cebolas e pontas de gordura e que o grelhasse "na sertã". O Jesus de Cavanna chamou a última refeição de "o sacrossanto sacrífico da missa". Jesus reco-

20. “14. E havia também Lázaro, o irmão de Marta e de Maria Madalena, que Jesus tinha ressuscitado depois de ele ter estado quatro dias morto entre os mortos, e que tinha conservado as bochechas chupadas, e a cara um bocado verde e a narina um bocado abundante de larvas,

15. E havia também samaritanos e hemorróissas, e surdos-mudos e cegos,

16. E coxos, papeirosos, leprosos, empestados, tinhosos, ranhosos, urinados, crostosos, dementes, diarreicos, vasentos, vesgos,

17. E possessos, raivosos, sifonosos, pomadosos, queimados,

18. E filhos-pródigos, pais indignos, mães alcoviteiras, filhas públicas, irmãos siameses, bebés-foca, demônios arrependidos, camelos que tinham tentado passar pelo buraco de uma agulha,

19. E fariseus, publicanos, radical-socialistas, pederastas, cavalheiros da indústria, funcionários ministeriais, toureiros, labregos, tosquiadores de cães, castradores de gatos, circuncisos-jurados, anti-semitas, peraltas, sapateadores, finos gastrônomos, messias que tinham tentado o golpe mas que não tinham tido sorte,

20. E perdulários, basbaues, cus-rasteiros, papa-almoços, espreitas, beberrões, ressonadores, impotentes, terçóis, mija-três-gotas, marias-porcas,

21. E pessoas que tinham saído para comprar fósforos, e pessoas que tinham saído para se irem afogar." CAVANNA, 1986, p. 247.

21.26. "[...] Judas, meu velho porco, tu farás de traidor". CAVANNA, 1986, p. 253.

22. “8. 'Traia, nós faremos o resto'”. CAVANNA, 1986, p. 254. 
mendou ainda aos discípulos que repetissem o ofício todos os dias e que aos domingos o fizessem com mais decoração. A última ceia do Evangelho segundo Cavanna foi um verdadeiro menu completo: como aperitivo, comeram "camarões e mexilhões"; o prato principal era o corpo de Jesus e a bebida o seu sangue; por fim, antes de irem "arrotar no Jardim das Oliveiras", desfrutaram de uma sobremesa enquanto cantarolavam cantigas antigas.

No Getsêmani, após dizer aos discípulos que precisaria ir para um lugar no qual nenhum deles poderia e "passar o bastão" para Pedro ("5. Et Jésus dit : 'Pierre, de tous mes apôtres tu es le plus vieux, tu es le plus bête, tu es le plus sale, tu es le plus chauve, tu es le plus paresseux, tu es le plus lâche et tu es le plus vantard, 6. Mais aussi tu es le plus lèchecul. C'est pourquoi je t'honore de ma confiance et t'ai mis à la tête de mon Église [...]"'23 (CAVANNA, 2002, p. 320)), Jesus confirmou o seu favoritismo pelo discípulo concedendo-Ihe, como presente, a "Infalibilidade pontifícia”. Também no Getsêmani, tal como em Mt 26:38, Jesus foi tomando por profunda tristeza. Após ter orado ao Pai e ter pedido que o funesto desígnio lhe fosse afastado (a narrativa do cálice, Mt 26:39), o "Eterno" enviou um anjo a Jesus, que lhe disse o seguinte: "9. '[...] Ton Père te fait dire ceci : Merci mille fois pour la permission, mais quant à la chose du calice d'amertume, pas question de changer de programme'"24 (CAVANNA, 2002, p. 323).

Depois de entreter os discípulos com seus poderes fantásticos, certamente para espraiar a atmosfera fúnebre, diz o Evangelho de Cavanna que Jesus fez sair de si mesmo suor de sangue e que de suas orelhas jorraram duas pequenas fontes de sangue, cujo vermelho brilhava à luz

23. "5. E Jesus disse: 'Pedro, de todos os meus apóstolos, tu és o mais velho, és o mais estúpido, és o mais porco, és o mais calvo, és o mais preguiçoso, és o mais cobarde e és o mais vaidoso, 6. Mas também és o mais lambe-cus. É por isso que te honro com a minha confiança e te pus à cabeça da minha igreja [...]'" CAVANNA, 1986, p. 261.

24. "9. '[...] O teu Pai manda dizer isto: Mil vezes obrigado pelo consentimento, mas quanto àquilo do cálice de amargura, não vamos alterar o programa'”. CAVANNA,1986, p. 263. 
da lua. $E$ tendo sido perguntando por eles se saberia fazer o truque das cartas, a tropa de romanos chegara sob a companhia de Judas. O traidor, como alguém que desejava que um roteiro fosse literalmente comprido e "qui était un peu gras du bide et plutôt court de souffle"25 (CAVANNA, 2002, p. 325), pedira para que todos esperassem por ele: '[...] Attendezmoi ! Attendez-moi ! Vous ne pourrez rien faire sans moi !'26 (CAVANNA, 2002, p. 325). Tendo declarado ser o Messias, o Filho de Deus e o Rei dos Judeus, o centurião deu voz de prisão a Jesus em nome da Lei e dos Profetas. Judas, que havia chegado um pouco atrasado sobre a cena, disse a Jesus: 'Je vais vous trahir ça vite fait !'27 (CAVANNA, 2002, p. 325). Diz o Evangelho de Cavanna que Judas elevou-se na ponta dos pés para beijar Jesus, mas antes ouviu do mestre: 'Pas sur la bouche !'28 (CAVANNA, 2002, p. 325). E Judas beijou-o nas bochechas, três vezes, fazendo estalar muito alto os beijos, pois gostava de obras bem-feitas.

Depois de ser conduzido até Caifás e a Pôncio Pilatos, diz o Evangelho de Cavanna que este último teve piedade de Jesus. Pilatos, sem saber o que fazer com Jesus, propôs à multidão: “"[...] Écoutez, je vais lui faire donner une petite fessée [...]"'29. Diz o Evangelho que todos ficaram contentes com a ideia, mas queriam também a morte do salvador. Pilatos, assim diz o texto, "[...] fut contrarié de voir ces Juifs aussi carnassiers [.... $]^{30}$.

Não vendo outra alternativa, Pilatos propôs então, por ser páscoa, que a multidão que decidisse que prisioneiro libertar. Tal como em Mt 27:15-21, tratava-se de soltar Jesus ou Barrabás. Diz o Evangelho de Cavanna que a multidão teve uma só voz e gritou pelo nome do segundo.

Indignado pela escolha, Pilatos, curioso, perguntou-Ihes o porquê

25. "2. [...] que era um pouco gordo do ventre e curto de fôlego [...]" CAVANNA, 1986, p. 265.

26. "2. '[...] Não podem fazer nada sem mim!'” CAVANNA, 1986, p. 265.

27. "7. '[...] Vou-te trair já está!” CAVANNA, 1986, p. 265.

28. "8. '[...] Na boca não!" CAVANNA, 1986, p. 265.

29. "14. 'Escutem, umas palmadas no rabo [...]"' CAVANNA, 1986, p. 270.

30. "16. [...] ficou contrariado por ver aqueles judeus tão carniceiros [...]" CAVANNA, 1986, p. 270. 
de decidir pela morte de Jesus. E as respostas foram as mais variadas, diz o texto:

22. Et les uns dirent : 'Parce qu'il a les cheveux longs.' Et d'autres dirent : 'Parce qu'il porte la raie sur le côté'. D'autres : 'Parce qu'il a un grain de beauté sur la joue droite'.

23. D'autres: 'Parce que nos femmes prononcent son nom lorsque nous forniquons avec elles au lieu de faire attention à ce qu'elles font'. D'autres : 'Parce qu'il a l'air d'une tante'. D'autres : 'Parce qu'il en sait trop'. D'autres : 'Parce qu'il a une bonne gueule de crucifié'.

24. D'autres : 'Parce qu'on n'a pas de nègres, par ici'. D'autres : 'Parce que ça serait trop dangereux de crucifier des Romains'. 25. D'autres : 'Parce qu'on aime bien crucifier les gens'. D'autres : 'Parce qu'on en a marre de les empaler'.

26. D'autres : 'Parce que c'est un bon exemple pour l'éducation de la jeunesse'.

27. D'autres : 'Parce qu'une croix c'est plus joli quand il y a un crucifié dessus, moi je trouve'.

28. D'autres : 'Parce qu'on est sains et sans problèmes'. D'autres : 'Parce qu'il faut bien que jeunesse se passe'. D'autres : 'Parce que, bof, mourir de ça ou d'autre chose...' 29. D'autres : 'Parce qu'on est charpentiers en croix'. D'autres : 'Parce qu'on est forgerons en clous'. D'autres : 'Parce qu'on est des mouches à viande, bzz, bzz...'

30. Et tous ensemble dirent : 'Surtout parce qu'il est innocent, et que c'est bien meilleur quand ils sont innocents's1

(CAVANNA, 2002, p. 333).

31. '22. E uns disseram: 'porque tem cabelos compridos.' E outros disseram: 'Porque tem risco ao lado'. Outros: 'Porque tem um sinal na bochecha direita'.

23. Outros: 'Porque as nossas mulheres pronunciam o seu nome enquanto fornicamos com elas em vez de prestarem atenção ao que estão a fazer.' Outros: 'Porque tem ar de tia'. Outros: 'Porque sabe demasiado'. Outros: 'Porque tem cara de crucificado'.

24. Outros: 'Porque não há negros por aqui'. Outros: 'Porque seria muito perigoso crucificar romanos'.

25. Outros: 'Porque gostamos muito de crucificar pessoas'. Outros: 'Porque nos divertimos a empalhá-las'.

26. Outros: 'Porque é um bom exemplo para a educação da juventude'.

27. Outros: 'Porque uma cruz é mais bonita quando tem um crucificado, eu cá acho'.

28. Outros: 'Porque estamos sãos e sem problemas'. Outros: 'Porque é preciso que a juventude passe por essas coisas'. Outros: 'Porque, bah, morrer disso ou de outra coisa...'

29. Outros: 'Porque somos carpinteiros de cruzes'. Outros: 'Porque somos ferreiros de pregos'. Outros: 'Porque somos moscas da carne, bzz, bzz...'” CAVANNA, 1986, pp. 270-271. 
A crucificação - que no Evangelho de Cavanna não acontece para Jesus e que hipertextuamente transforma e subverte a teleologia dos Evangelhos bíblicos - aparece no capítulo 11, epílogo da obra, como uma espécie de ruptura do horizonte de expectativa. Tendo sido entregue aos soldados para a crucificação, Jesus foi vestido com um manto escarlate. Sobre sua cabeça puseram ainda a coroa de espinhos (Mt 27:29). Antes que se inicia-se de vez não a via da morte, mas a da fuga, Pilatos pediu aos soldados que fossem corteses com o condenado, isto porque sua esposa tinha sonhado com Jesus e pronunciado o nome do Filho de Deus em sua cama. Pilatos não desejava - assim diz o Evangelho de Cavanna - que pensassem que crucificação fosse apenas um pretexto em razão de ciúmes.

O Evangelho de Cavanna detalha ainda que a condução da própria cruz por parte de qualquer condenado à crucificação, até o local do definitivo suplício, se tratava de algo previsto tanto nos "Profetas", quanto no "Regulamento Geral de Enforcamentos, Crucificações, Festas e Fogosde-Artifício" da Cidade de Jerusalém. Assim passou a ser logo em razão "[...] de haute lutte par les aides-bourreaux à la suite d'une grève longue et dure où ils montrèrent une conscience de classe et une discipline qui forcent le respect"32 (CAVANNA, 2002, p. 338).

Deram a Jesus - assim narra texto - “ [...] une croix réglementaire modèle Marius modifié Sylla, en bois d'olivier premier choix, sans nœuds ni malfaçon, chevillée plein bois, avec chanfreins et moulures conformes au modèle, côté face soigneusement poli au papier de verre numéro double zéro pour éviter tout risque d'échardes, et, en option, petit support en pente douce pour les pieds (supplément selon pointure)"33 (CAVANNA,

32. "1. [...] por dura luta dos ajudantes de carrasco na sequência de uma greve longa e dura em que mostraram uma consciência de classe e uma disciplina que obrigam a respeitá-los". CAVANNA, 1986, p. 275.

33. "2. [...] uma cruz modelo Marius versão Sylla, em madeira de oliveira de primeira qualidade, sem nós nem defeitos, maciça, chanfrada e emoldurada conforme o modelo, lado frontal cuidadosamente polido com lixa zero-zero para evitar todos os riscos de farpas, e, em opção, um pequeno suporte em declive ligeiro para os pés (suplemento por medida)". CAVANNA, 1986, p. 275. 
2002, p. 338). Após atestar que a cruz correspondia ao modelo descrito no catálogo e ter verificado o bom estado da mesma, "Jesus, étant charpentier de son métier, apprécia le travail en connaisseur, et il cligna de l'œil pour viser si la croix était bien droite, et puis il cracha dans ses mains, et il mit la croix sur son épaule, et il dit : 'Bon. On y va ? C'est que j'ai le monde à sauver, moi'”34.

Tendo tropeçado, Jesus caiu e sobre ele a cruz. É neste momento que a narrativa de Cavanna traveste e reescreve a dos Evangelhos com grande criatividade artística. Convocando explicitamente o texto de $\mathrm{Mt}$ 27:32, Cavanna inscreve Simão de Cirene no plano da narrativa. Ele o apresenta como um homem que ia a Jerusalém todos os anos para a páscoa, porque os bordeis desta cidade eram mais belos do que os de sua cidade natal. Quando o soldado ordena a Simão que carregue a cruz, ele lamenta para si mesmo em seu próprio íntimo, diz o Evangelho de Cavanna, por não ter ficado em Cirene e ter tomado um café da manhã na cama e ter se masturbado. Jesus, por sua vez, diz a Simão de Cirene que só a cruz não bastava e então colocou-lhe a coroa de espinhos: '[...] tiens, ceci va avec'35, disse Jesus (CAVANNA, 1982, p. 340).

É neste momento que o herói de Cavanna se aproxima da figura literária do trickster. ${ }^{36}$ Como bem sublinha Cristina Azuela (2011, p. 31), os tricksters se caracterizam pelas suas inclinações transgressoras e que derivam do uso de artifícios astuciosos. Adorado e seguido por aqueles que obtém seus pequenos favores e milagres (uma das facetas mais conhecidas do trickster é a de ser dotado de poderes sobrenaturais) e hostilizado pelos representantes da manutenção da ordem social e religiosa, o Jesus de Cavanna "encarna" esta figura mítica e literária em razão da

34. "4. E Jesus, sendo carpinteiro de profissão, apreciou o trabalho como um conhecedor, e fechou um olho para ver se a cruz estava bem direita, e depois cuspiu nas mãos, e pós a cruz aos ombros, e disse: 'Bem. Vamos? É que eu tenho o mundo para salvar'”. CAVANNA, 1986, pp. 275-276.

35. "21. '[...] Toma, pertence ao conjunto'”. CAVANNA, 1986, p. 277.

36. Um belo texto acerca da figura literária do trickster é o de Cristina Azuela. Cf. AZUELA, Cristina. Quelques traces du trickster dans la littérature médiévale. Grenoble, Revue IRIS, n. 32, 2011, pp. 29-58. 
astuta engenhosidade empregada para desviar-se da sua missão. Se a vinda do Jesus de Cavanna ao mundo estava a serviço da salvação da humanidade perdida, esta personagem salvaria antes a si mesmo. $\mathrm{O}$ Jesus de Cavanna - um tipo de "héroi trapaceiro" ${ }^{37}$, como bem definiria Renato da Silva Queiroz (1991) - usou da astúcia, trapaceou com os céus - porque na primeira oportunidade passou adiante o cálice (além da cruz, entregou a Simão de Cirene a coroa de espinhos) - e escapou de modo engenhoso da tarefa de ter de morrer para salvar o mundo. Entre as mulheres que acompanhavam a "meia" Via Crucis de Jesus encontrava-se Verônica, que segundo o Evangelho de Cavanna seria da cidade de Polahr-Ohid. A Verônica de Cavanna - assim narra o texto limpou o rosto de Jesus com um lenço e após deu-se conta de que o rosto do Filho de Deus estava nitidamente estampando, inclusive em cores.

O cortejo da crucificação prosseguia e depois de tanta confusão, as pessoas confundiram Simão de Cirene, que então portava a cruz e a coroa de espinhos, com Jesus. Chegando ao Gólgota - tudo sob o olhar do herói das reescrituras de Cavanna - os soldados, não dando-se conta de que o barbudo que levava a cruz não era Jesus, nela pregaram Simão. E de longe presenciando a crucificação de Simão de Cirene, Jesus, depois de muito pensar, olhou para os céus e disse: "Mon Père, pardonne-leur, car ils ne savent pas ce qu'ils font"38 (CAVANNA, 2002, p. 342). O Evangelho de Cavanna narra ainda que Simão de Cirene teria gritado o seguinte: “[...] Éli ! Éli ! Lamma sabacthani !' ce qui est du cyrénaïcain littéraire et signifie : 'Si j'aurais su, j'aurais pas venu, merde, alors !'39

O Jesus de Cavanna, ao final do longo périplo, se livra da morte, mesmo que às custas da crucificação de Simão de Cirene. Diz o Evangelho de Cavanna que Maria Madelena e Jesus, depois se afastarem de toda

37. Cf. QUEIROZ, Renato da Silva. O héroi-trapaceiro. Reflexões sobre a figura do trickster. São Paulo, Tempo Social, v. 3, n.1-2, 1991: 93-107.

38. “9. '[...] Perdoai-Ihes, meu Pai, que eles não sabem o que fazem'”. CAVANNA, 1986, p. 278.

39. “19. '[...] Eli! Eli! Lamma sabachani!' o que é cirenaico literário e significa: 'Se tivesse sabido não vinha, merda!"” CAVANNA,1986, p. 279. 
a multidão, viveram felizes e tiveram muitos filhos.

\section{Conclusão}

Numa perspectiva estética, LAPJ só alcançam o seu estatuto de obra, isto é, o seu modo de existência enquanto obra literária, sob a participação dos Evangelhos bíblicos - sobretudo o de Mateus - enquanto sua principal matéria prima. Chamamos tal condição de existência de participação estética. Portanto, não seria possível olhar LAPJ, em particular, e conceber que os seus capítulos e versículos estão apenas a serviço da iconoclastia, da crítica e da ridicularização da religião ou da Bíblia ou ainda a serviço daquilo que Nella Arambasin (1996, p, 221) chamou de esvaziamento do sentido trágico dos Evangelhos, em referência à estética Alfred Jarry. Certamente, Nella Arambasin pensava no texto de 1903, La passion considérée comme course de côte. Neste sentido, o ângulo de análise da cena artística contemporânea adotado por Grenier (2003) é mais interessante. Diríamos, em síntese, que é preciso considerar que LAPJ são antes uma criação artística que não só reinscreve a personagem Jesus na literatura do nosso tempo, mas também reescrevem as narrativas acerca dessa importantíssima personagem.

Na obra de Cavanna, as operações hipertextuais não se estabelecem somente a partir dos Evangelhos bíblicos. Se pensarmos, por exemplo, no episódio em que Judas apresenta o seu plano de traição ao escriba, veremos que a alusão ao "moinho de vento" - figura literária imortalizada por Miguel de Cervantes - evoca o quixotesco, isto é, a drôlerie tão cara às obras que se vocacionam ao humor, ao satírico, ao burlesco.

A narrativa de Verônica seria um outro exemplo de hipertextualidade para além dos Evangelhos bíblicos. É de Alfred Jarry que Cavanna toma o hipotexto. Sob o título La passion considérée comme course de côte, Alfred Jarry transforma a via sacra de Jesus em uma "competição de ciclismo". Nessa pequena história de Jarry (1969, pp. 356-359), Verônica torna-se uma repórter que faz a cobertura fotográfica de uma corrida de 
bicicletas com sua Kodak. Em Cavanna, a referência à marca da máquina fotográfica é designada pelo vocábulo Polahr-Ohid. Muito conhecida pela fabricação de máquinas para fotografias instantâneas, a marca Polaroide, em Cavanna, dá nome à cidade de origem da personagem Verônica. O que está em jogo, é claro, não são propriamente as marcas Kodak (em Jarry) e Polaroide (em Cavanna). Ao evocarem esta personagem feminina, Cavanna e Jarry exploram de maneira lúdica e criativa a légende do véu de Verônica.

O Jesus de Cavanna é demasiado humano. Propõe charadas aos discípulos, usa seus poderes sobre-humanos para resolver problemas do cotidiano (como desentupir pias). O Jesus de Cavanna cura leprosos, paralíticos, ninfomaníacas, os que sofrem com as hemorroidas etc. $\mathrm{O}$ Jesus de Cavanna é um Jesus claramente tocado pela experiência do existir, tanto que hesita, declina e, por fim, escapa de modo engenhoso (à maneira de um trickster) da sua missão de salvar o mundo. Capaz de provocar o riso e de dizer não para a cruz, porque foi criativamente travestido pelo seu reescritor da mais mundana humanidade, o Jesus de Cavanna, herói-cômico e astuto com um trickster, evoca, para além do grande mistério da ressureição, uma grande paixão pela vida.

\section{Referências bibliográficas}

ARAMBASIN, Nella. La conception du sacré dans la critique d'art en Europe entre 1880 et 1914. Genève: Droz, 1996.

AZUELA, Cristina. Quelques traces du trickster dans la littérature médiévale. Grenoble, Revue IRIS, n. 32 (Espaces Mythiques), 2011.

CAVANNA, François. As Sagradas Escrituras. Publicações Dom Quixote: Lisboa, 1986.

CAVANNA, François. Les Écritures: les aventures de Dieu et du petit Jésus. Paris: Albin Michel, 2002.

GENETTE, Gérard. Palimpsestes: la littérature au second degré. Paris: Éditions du Seuil, 1982.

GENETTE, Gérard. Seuils. Paris: Éditions du Seuil, 1987.

GENETTE, Gérard. L’CEuvre de l'art. Paris: Éditions du Seuil, 2010. 
GERVEREAU, Laurent. Voir, comprendre, analyser les images. Paris: La Découverte, 1997.

GRENIER, Catherine. L'art contemporain est-il chrétien? Nîmes: Jacqueline Chambon, 2003.

JARRY, Alfred. La chandelle verte. Paris: Librairie Générale Française, 1969.

KRISTEVA, Julia. Introdução à semanálise. São Paulo: Editora Perspectiva, 1974

LOSCO-LENA, Mireille. Tragique et comique sur les scènes contemporaines: pour une "poétique complexe". Publications numériques du CÉRÉdl (Actes de colloques et journées d'étude. Rouen, n. 7, 2012: 1-11. Disponível em: http://ceredi.labos.univ-rouen.fr/public/IMG/pdf/LOSCO LENA. pdf. Acesso em 24. 02. 2020.

QUEIROZ, Renato da Silva. O héroi-trapaceiro. Reflexões sobre a figura do trickster. São Paulo, Tempo Social, v. 3, n.1-2, 1991: 93-107. Disponível em: http://www.scielo.br/pdf/ts/v3n1-2/0103-2070-ts-03-02-0093. pdf. Acesso em 08. 02. 2020.

SARRAZIN, Bernard. La Bible parodiée. Paris: Les Éditions du Cerf, 1993.

SILVA, Eli Brandão da; LUNA, Huerto Eleutério Pereira de. Salmos e Evangelhos por paródias, em poéticas de Luis Augusto Cassas e Murilo Mendes. Estudos de Religião, São Bernardo do Campo, v. 33, n. 3, 2019: 15-35. Disponível em: https://www.metodista.br/revistas/revistas-ims/index. php/ER/article/view/9911/7 058. Acesso em: 21. 02. 2020.

SILVA, Eli Brandão da. O nascimento de Jesus-Severino no auto de natal pernambucano como revelação poético-teológica da esperança: hermenêutica transtexto-discursiva na ponte entre teologia e literatura. 2001. 284 f. Tese (Doutorado em Ciências da Religião). Universidade Metodista de São Paulo, São Bernardo do Campo, São Paulo.

ZUMSTEIN, Jean. Intratextualité et intertextualité dans la littérature johannique. In: CLIVAZ, Claire [et al.]. Écritures et réécritures: la reprise interprétative des traditions fondatrices par la littérature biblique et extra-biblique. Peeters: Leuven, 2012. 